\title{
A Study on High School Chemistry Teachers’ Meta-Teaching Ability
}

\author{
Dai Jing-ran, Jin Ying \\ Tianjin Normal University, Tianjin, China
}

\author{
Wu Kai-lun \\ Tianjin 43rd High School, Tianjin, China
}

\begin{abstract}
The high school chemistry teachers with meta-teaching ability can reflect on the value of the chemistry knowledge and their teaching based on a proper methodology, so as to guide the students professionally and efficiently in chemistry teaching. Among the six facets of understanding, "to have perspective," "to empathize," and "to have self-knowledge” can show teachers’ meta-teaching ability.

Keywords: meta-teaching, chemistry, understanding
\end{abstract}

\section{Introduction}

In order to solve the Comete paradox, Alfred-Tarlski, a philosopher, put forward the concept of "meta" in 1956. In his opinion, "meta-what" refers to "whatever about whatever" (Jiang, 2007).

Edgar Moran (1921- ) said, "Any concept system inevitably involves some questions beyond the system” (Chen, 2002). Therefore, the survey on a system should be based on the meta-system, which also goes to the teaching system. Undoubtedly, meta-teaching is a system which can enable teachers to review what teaching is and how to teach. The more important is that meta-teaching can also enable teachers to rethink the value of knowledge, the effect of knowledge on students, and how to help students acquire numerous and diverse chemistry knowledge. To chemistry teachers, that is how to transform the specific chemistry knowledge into chemistry concept and how to cultivate students' chemical literacy. To study the meta-teaching ability of high school chemistry teachers, we should know what meta-teaching is and on what aspects will a high school chemistry teacher's meta-teaching ability show. As a matter of fact, these questions are also the things that this paper concerns.

\section{The Connotation of Meta-Teaching}

"Meta” means "after" or "transcend.” It is an advanced form of logic, and it has two meanings. "The first one is that this logical form has a transcendent and speculative nature. The other is that this new high-level logical form examines the nature, structure and other manifestations of the original discipline in a critical perspective” (Tang, 2002).

As a technical term, meta-teaching was described by English and it has been frequently quoted in some studies by British and American scholars. However, as for its definition, there is little systematic explanation or discussion about it. The author has studied the writings and papers related to meta-teaching, only to find two

Dai Jing-ran, M.A., student, Teacher Education Department, Tianjin Normal University. Jin Ying, Ph.D., professor, Teacher Education Department, Tianjin Normal University. Wu Kai-lun, B.S., teacher, Chemistry Department, Tianjin 43rd High School. 
papers about meta-teaching. One is “The meta-teaching research” by Chen (2011). The other is "The promoting effect of English Linguistics in English teaching from the perspective of meta-teaching” by Zhang and Ai (2012). Of the two, Chen's (2011) paper is the synthesizer of meta-teaching. In his paper, he interpreted meta-teaching from three aspects: (1) Firstly, the definition of "meta-", meta-learning and the understanding of teaching, and defines meta-teaching; (2) Secondly, he pointed out the function of meta-teaching; and (3) Lastly, he rethinked the absence of meta-teaching in practical teaching, and offers the meta-teaching strategy.

In Chen's paper, he held, "Meta-teaching is the understanding and reflection on teaching based on the definition of 'meta.' It is a teaching about teaching, a teaching that the teacher can teach, and a conscious teaching based on the teaching of thinking and aimed at teaching practice" (Chen, 2011). From his definition, we can know that he defined meta-teaching by interpreting "meta-what" as "whatever about whatever," and he thought meta-teaching is teaching about teaching and his ultimate goal is "teaching”. However, meta-teaching should be based on the rational level of philosophy, so its foothold should be on the level of thinking instead of the practical level.

In summary, meta-teaching is understanding and reflection on the teaching based on the "meta" view, and it is the reflection on teaching reflection standing in the height of philosophy. As for the subject of chemistry, high school chemistry teachers' meta-teaching ability is understanding and reflection on chemistry knowledge and the teaching reflection based on "meta" view, the philosophy of chemistry and the teaching of philosophy. From its definition, meta-teaching requires teachers to reflect on their teaching and teaching reflection, that is, "Why do you teach students such knowledge? What is the role of the knowledge to students' growth and development? How to turn the chemistry knowledge into basic chemistry concepts in teaching?”, and so on.

\section{Embodiment of Teachers' Meta-Teaching Ability}

Unlike teachers' chemical knowledge shown by paper test, or teaching and skills reflected by a few minutes lecture, the teachers' meta-teaching ability is reflected in the concept level and reflection level. Investigating the related researches, we can know that teachers' meta-teaching ability can be reflected on their understanding to a great extent. Therefore, we use the six facets of understanding as a tool to measure the high school chemistry teachers' meta-teaching ability (see Table 1).

Table 1

The Six Facets of Understanding

\begin{tabular}{|l|l|}
\hline Can explain & $\begin{array}{l}\text { ia generalizations or principles, providing justified and systematic accounts of phenomena, facts, and data; } \\
\text { make insightful connections and provide illuminating examples or illustrations. }\end{array}$ \\
\hline Can interpret & $\begin{array}{l}\text { tell meaningful stories; offer apt translations; provide a revealing historical or personal dimension to ideas } \\
\text { and events; make the object of understanding personal or accessible through images, anecdotes, analogies, } \\
\text { and models. }\end{array}$ \\
\hline Can apply & effectively use and adapt what we know in diverse and real contexts-we can "do" the subject. \\
\hline Have perspective & see and hear points of view through critical eyes and ears; and see the big picture. \\
\hline Can empathize & $\begin{array}{l}\text { find value in what others might find odd, alien, or implausible; perceive sensitively on the basis of prior } \\
\text { direct experience. }\end{array}$ \\
\hline $\begin{array}{l}\text { Have } \\
\text { self-knowledge }\end{array}$ & $\begin{array}{l}\text { show metacoganitive; perceive the personal style, prejudices, projections, and habits of mind that both shape } \\
\text { and impede our own understanding; are aware of what we do not understand; and reflect on the meaning of } \\
\text { learning and experience. }\end{array}$ \\
\hline
\end{tabular}

Note. Source: Wiggins \& McTighe (2005).

Through the six facets of understanding, we can see that the first three facets: "to explain," "to interpret," and "to apply" focus on the cognitive level. The last three: "to have perspective," "to empathize," and "to have 
self-knowledge" can show the teachers' concept and the reflection level, which are the reflection of teachers' meta-teaching ability. From the six facets of understanding, an analysis is made on the video of a micro lecture by an outstanding teacher.

\section{Case Analysis of High School Chemistry Teacher's Meta-Teaching Ability}

In this paper, the case is based on the second period of Section 2, Chapter 4: The Comprehensive Utilization of Resources \& Environmental Protection, from Chemistry Compulsory Textbook of high school, published by People's Education Publishing House.

\section{The Analysis of the Micro Record}

\section{Episode1}

Our country has a plenty of fresh water, and Taihu is the third largest lake in China. It belongs to the national scenic area, and is one of the birthplaces of the Chinese culture. Now, let us step into Taihu through a video.

Title: Taihu's yesterday and today

The status quo of Taihu today forces us to face such a problem: If the car is dirty, we can use water to wash it. If the road is dirty, we can use water to clean it. But, if the water is dirty, what can we use to purify it? With this question, let us begin our lesson: Environmental Protection-Water Bloom.

Analysis: The teacher introduces the theme through current affairs. The contrast of Taihu's yesterday and today gives students a strong visual impact. The beautiful Taihu is now covered with blue-green algae. This may stimulate the students' desire to explore its causes. After watching the video, a simple and difficult question is posed, "If the water is dirty, what can we use to purify it?" The question seizes the nature of the problem. It makes the students have a feeling of panic over the present situation of the water pollution. Therefore, the students will be eager to find out ways and principles by which to control the water pollution. This question shows the teacher's meta-teaching ability.

\section{Episode 2}

$\cdots$

What can we do to face the increasingly serious pollution? In fact, there are many things we can do to save and protect the domestic water. First, let us watch the video about "the application and sales of the detergent" produced by the students of the learning team.

Title: The Application and sales of the detergent (Produced by the teacher)

This is the final summary report on the activities of the group. (Power Poiont [PPT])

After watching the video, we have to think about a question. Are the salesman's market focus and customers' selection criteria reasonable? To answer the question, let us learn the principle of washing process by learning sodium alkylsulfonate, the main component of detergent.

In the washing progress, the hydrophilic group combines with water firstly, and the lipophilic group goes slowly into the water, then the lipophilic group seizes the grease, and finally, the hydrophilic group moves towards the water. ... In order to enhance washing effect, people often add a certain proportion of phosphate to the detergent in the actual production process. Though phosphate is a good builder, it is also a good algae growth substance. According to the authoritative survey, the discharge of phosphorus compounds in the 
washing powder causes eutrophication in most of the lakes and coastal waters in China. Can you realize that the charmingly bagged washing powder is the pollution source? The exquisitely packaged detergent is the killer of the environment? Though we can not refuse washing, we can choose the detergent which is friendly to the environment. We can make environment friendly as a standard when we choose detergent. Therefore, in order to prevent water bloom, we advocate non-phosphorus detergent.

Analysis: Through the investigation, the students understand the ingredient of detergent, the key spot of salesman, and the purchase criteria of consumers. They can realize that the detergent has a bad effect on water in our daily life, and that non-phosphorus detergent is good for water. So, they may choose the non-phosphorus detergent and urge others to buy non-phosphorus detergent. At the same time, the students can improve their ability to communicate and cooperate with others, and can increase their interest in learning chemistry. A student said, "In this activity, I have practised my communication, and begin to be interested in learning chemistry, too. I think I will be very glad to take part in such activities in future classes.” Through this method, the teacher shows the close connection between chemistry and life, and helps students realize that chemistry is closely linked with life, and the knowledge which has been learnt in the classroom would have a great effect on our daily life. Therefore, the teacher, who is good at thinking and finding out the nature of the problem, the textbook knowledge can apply to life easily. In a word, it is also the reflection of meta-teaching ability.

\section{Episode 3}

...

It is time that people did something to control the pollution. The measures are: salvaging the blue-green, piping water from the Yangtze River into Taihu, and developing the lake dredging project. Now, some of you may be worried: If the salvaged blue-green algae are simply accumulated on the land, they will turn into a new green waste. How to avoid the new form of pollution? In July, 2015, the technicians studied a new way to control this pollution-The blue algae biogas power generation. It makes the blue-green algae harmless and resources salvaged. At the same time, it tells us that garbage is the misplaced resources, and we should make use of science and technology to turn the waste into resources.

Analysis: The teacher starts from the timely treatment of Taihu Lake blue-green algae, and continues with the news of blue algae biogas power generation, finally, he comes to the conclusion with the idea-Garbage is the misplaced resource. So, the students can be aware of the rational use of resources. At the same time, they realize the importance of science and technology. What is more, they realize the importance and urgency of learning, finally, they can realize the mission of a new generation of citizens.

\section{Episode4}

$\cdots$

Taihu Lake cyanophyta comes to an end, but what Taihu's tomorrow and the future of the planet will be? This incident left us thinking far from over. The beautiful scene is not an album of pictures, but the environment around us. So, let us start from little things: advocate non-phosphorus detergent to the people around us and explain our reason to them, put forward more prevention suggestions about phosphorated detergent in the perspective of "turning garbage into resources".

Analysis: Environmental protection is more than class activities in the classroom, everyone should do something from little things. The assignment by the teacher is to urge students to enhance the awareness of environmental protection in actual operation, so it can achieve the goal of understanding and applying the knowledge. 


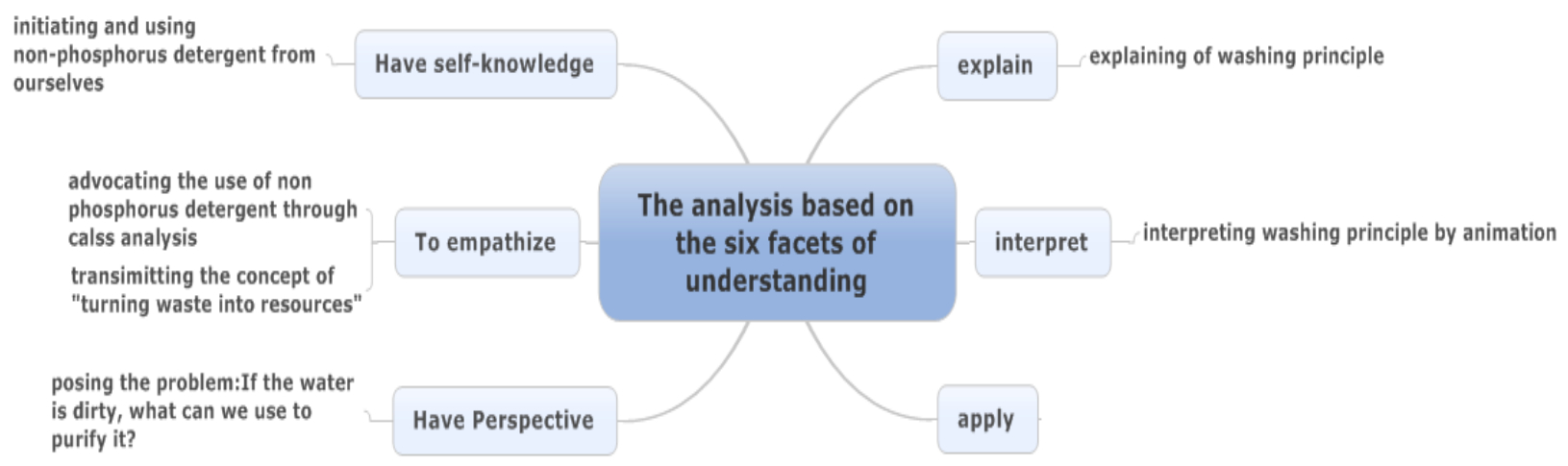

Figure 1. The analysis based on the six facets of understanding.

\section{The Analysis Based on the Six Facets of Understanding}

From Figure 1, it can be seen that in this 10-minute micro-lecture, the teacher does not only focus on students' cognitive level of understanding and static knowledge, but also impregnates the teacher's reflection of the value of knowledge, the delivery of the related concepts, and the deep understanding of the teacher's teaching reflection. Therefore, it will enable students to learn in the concept level, achieve the goal of controlling the knowledge reasonably, and apply it into practical life.

This micro lecture relates two facets of understanding: "to explain" and "to interpret", and it focuses more on the concept of knowledge and the level of thinking. Since this section is not significant as far as test is concerned, it is not stressed in class by most teachers. However, environmental problems are closely related to human life and the development of future. It must be an important issue which cannot be ignored nowadays, and it also should be the focus of the classroom. The four teaching fragments do not reflect the facet of "to apply," but this is not the weakness of the teaching design. The six facets of understanding of Dwiggins's is in parallel relationship. According to the nature of knowledge, we need not deliberately pursue comprehensive understanding, and we should cultivate the students' ability of "applying the learnt knowledge to flexible thinking and action” (Wiggins \& McTighe, 2005).

\section{Conclusion}

In today's social situation, a simple delivery of knowledge cannot meet the social development requirements of students, and the teachers should not aim at students' high marks simply. In the chemical class, teachers should transmit the concept of science and the concept of chemistry contained in chemistry knowledge to students. This requires high school chemistry teachers to have strong meta-teaching ability. However, meta-teaching ability is not accomplished at one stroke, it involves in teachers' personal discovery and construction in practice. It also requires of teachers' ability of harnessing knowledge, the ability of self-reflection. It is reflected on the knowledge processing, the control of class, and other aspects of self-cognition. Meta-teaching can promote teaching, it does not only help the students improve the knowledge level and skill level, but also guides the students with scientific concept and help the students improve the ability of rethinking knowledge, knowing themselves, realizing the value of knowledge, and reflecting themselves, so that students can grow into all-round developed talents. 


\section{References}

Chen, X. D. (2011). The meta-teaching research. Journal of Shaanxi Normal University (Philosophy and Social Science Edition), 1, 150-155.

Edgar, M. J. (1991). Methods: The concept. Y. Z. Chen (Trans.). (2002). Beijing: Peking University Press.

Jiang, Y. J. (2007). The theoretical and empirical studies on metacognition. Changchun: The Northeast Normal University Press. Tang, Y. (2002). Meta-education. Beijing: People’s Education Press.

Wiggins, G., \& McTighe, J. (2005). Understanding by design. Alexandria, V.A.: Association for Supervision and Curriculum Development.

Zhang, C., \& Ai, X. P. (2012). The promoting effect of English linguistics in English teaching from the perspective of meta-teaching. Journal of Tongren University, 7, 117-120. 